\title{
COMBATENDO FAKE NEWS: MAPEANDO PRÁTICAS DE VERIFICAÇÃO NO CORREIO BRAZILIENSE' ${ }^{1}$
}

\author{
Fighting Fake News: Mapping Fact-Checking Practices at Correio Braziliense \\ Combatiendo las fake news: mapeando prácticas de verificación en el Correio \\ Braziliense
}

Alberto Marques

Professor do Programa de Pós-graduação em Inovação em Comunicação e Economia Criativa alberto.marques@gmail.com

\section{Resumo}

Este artigo tem como objetivo apresentar o funcionamento do Núcleo de Verificação Correio Braziliense, a Agência Holofote. Trata-se de um estudo exploratório que busca trazer à tona práticas adotadas no processo jornalístico de verificação de notícias. Inicialmente, classificamos o material coletado em seis meses de trabalho do Núcleo usando as categorias propostas por Wardle e Derakhshan (2018). A partir dessa observação, fizemos entrevistas semiestruturadas com três profissionais do núcleo de checagem. Os dados coletados indicam que existem rotinas variadas no processo de verificação e que cada informação demandará um trabalho diferente.

Palavras-chave: Verificação. Fake News. Apuração. Correio Braziliense. Agência Holofote.

\begin{abstract}
This paper aims to show the operation of the fact-checking unit Correio Braziliense at Holofote agency. This is an exploratory study seeking to discuss adopted practices of news verification in Journalism. First, we classify six months of fact-checking at Correio Braziliense unit, using categories proposed by Wardle and Derakhshan (2018). Based on these observations, we conduct semi-structured interviews with three professionals from this center. The gathered data shows that routines exist within the fact-checking process and each information requires different fact-checking work.
\end{abstract}

Key words: Fact-Checking. Fake News. News Verification. Correio Brasiliense. Agência Holofote.

\footnotetext{
${ }^{1}$ Este trabalho faz parte do projeto Verificação dos conteúdos produzidos por cidadãos: análise e sistematização das rotinas jornalísticas, financiado pela Fundação de Apoio à Pesquisa do Distrito Federal (FAP-DF).
} 


\section{Resumen}

Este artículo tiene como objetivo presentar el funcionamento del Núcleo de Verificación Correio Braziliense, en la Agencia Holofote. Hacer referencia a un estudio exploratorio que busca presentar prácticas adoptadas en el periodismo para llevar a cabo el proceso de verificación de las noticias. Inicialmente, se clasificaron seis meses de trabajo del núcleo, usando las categorías propuestas por Wardle y Derakhshan (2018), y a partir de esta observación, se llevaron a cabo entrevistas semiestructuradas con tres profesionales del núcleo. Los datos recolectados muestran que existen rutinas en el proceso de verificación, y que cada información demanda un trabajo diferente.

Palabras clave: Verificación. Fake News. Escrutinio. Correio Brasiliense. Agência Holofote.

\section{INTRODUÇÃO ${ }^{2}$}

A circulação de informações falsas na sociedade é relatada antes mesmo do surgimento da imprensa (BURKHARDT, 2017; IRETON; POSETTI, 2018). A prática é continuada no século XV com a invenção da imprensa. A novidade, à época, era a rápida e ampla disseminação das informações e o controle da circulação dessa emissão. Com o desenvolvimento dos meios de comunicação, esse método passou a atingir um maior número de cidadãos, continuando o processo de difusão circunscrito aos donos dos meios de produção da informação.

O ato disruptivo dessa lógica acontece com a criação, a evolução e a popularização da internet, aliada ao progresso da microeletrônica ${ }^{3}$, que possibilitou que quaisquer membros da sociedade civil com acesso a dispositivos conectados à internet pudessem produzir e circular informações de alcance global. Lemos (2005) chama esse acontecimento de quebra do polo de emissão, fenômeno que altera os processos de produção, de criação e de circulação comunicacionais nesse início de século XXI. Há uma reconfiguração dos fluxos nos processos informacionais e são constituídas novas formas de difusão das mensagens midiáticas (LEMOS, 2005).

Para este trabalho, é ponto central o impacto massivo das Fake News na sociedade contemporânea. É neste contexto que o jornalismo tem sido visto como um dos instrumentos de combate à desinformação. O paper tem como objetivo fazer um estudo exploratório do trabalho da Agência Holofote para começar a identificar práticas de verificação utilizadas por

\footnotetext{
${ }^{2}$ Uma versão deste artigo intitulada Verificando no jornalismo: mapeando práticas jornalísticas de combate a Fake News foi publicada nos Anais do $17^{\circ}$ Encontro Nacional de Pesquisadores em Jornalismo.

${ }^{3}$ Estamos nos referindo ao conjunto de aparelhos eletrônicos que passam a ser portáteis, gerando conteúdos digitais e móveis. Os dispositivos móveis são exemplos disso.
} 
jornalistas. A exploração iniciou-se com a categorização de notícias verificadas pela Holofote e a classificação dos conteúdos selecionados foi feita com base nos "tipos de notícias falsas" proposto por Wardle e Derakhshan (2018, p. 44).

O corpus de pesquisa foi construído a partir dos seis meses de produção da Holofote no primeiro semestre de 2019. Ao todo, foram 94 verificações classificadas. Essa coleta aconteceu no dia 26 de julho, seguida de três entrevistas semiestruturadas com os jornalistas que trabalham na editoria de checagem do Correio.

\section{FAKE NEWS}

O conceito de Fake News é polifônico (TANDOC; ZHENG; LING, 2018) e tem gerado diferentes interpretações no âmbito social. Um outro aspecto a ser elencado sobre a terminologia Fake News, é que ela tem sido usada por políticos e instituições de todo o mundo para descrever coberturas jornalísticas de organizações noticiosas consideradas por eles como desagradáveis. "Dessa forma, tem sido um mecanismo que os poderosos têm utilizado para minar a liberdade de imprensa" (WARDLE; DERAKHSHAN, 2017, p. 5) ${ }^{4}$.

Wardle e Derakhshan (2018) consideram o termo simplista, por não tratar apenas de notícias falsas, mas de um ecossistema informativo que assume diferentes formatos e é produzido por uma variedade de instituições. Para os autores, trata-se de um fenômeno maior, chamado de desordem informacional (informational disorder) ${ }^{5}$. A proposta conceitual criada pelos autores proporciona diferentes estudos do fenômeno. Os polos de emissão e recepção estão envolvidos nesse processo.

O primeiro elemento que citamos são os tipos de desordem informacional, que os autores vão chamar de Informação Incorreta, Desinformação e Mal-informação (misinformation, disinformation e mal-information) (WARDLE; DERAKHSHAN, 2017). Na Informação Incorreta, não há intenção de causar dano e a pessoa acredita que está certa. É quando uma inverdade é publicada ou compartilhada por falsa conexão ou erro estatístico, por exemplo. Instituições públicas, privadas e cidadãos podem cometer esses erros. Título,

\footnotetext{
4 "In this way, it's becoming a mechanism by which the powerful can clamp down upon, restrict, undermine and circumvent the free press."

${ }^{5}$ Os autores defendem que o fenômeno afeta a credibilidade e o funcionamento de diferentes instituições sociais, principalmente o jornalismo.
} 
legenda ou elementos visuais podem provocar conexão falsa, quando não estão de acordo com o conteúdo.

O tipo dois, Desinformação, consiste em informações falsas produzidas e compartilhadas com o objetivo de prejudicar e tirar proveito. Normalmente, é um conteúdo impostor, fabricado com falso contexto ou mesmo contendo teorias da conspiração, "É uma mentira deliberada e intencional e aponta para as pessoas a serem ativamente desinformadas por agentes maliciosos" (WARDLE; DERAKHSHAN, 2018, p. 44) ${ }^{6}$. Trata-se de uma informação que, depois de publicada, revela-se difícil a identificação da intencionalidade de ludibriar.

A Mal-informação seria o elemento três, quando uma informação genuína é compartilhada para prejudicar de forma deliberada, normalmente tornando públicas informações privadas. São casos de vazamentos, assédio e discurso de ódio, por exemplo. Em outras palavras, são fatos relacionados a pessoas e transformados em acontecimentos de públicos. As autoras partem do pressuposto do interesse público da informação:

Um exemplo é um relatório que revela a orientação sexual de uma pessoa sem justificativa de interesse público. É importante distinguir mensagens que são verdadeiras daquelas que são falsas, mas também aquelas que são verdadeiras (e aquelas mensagens com alguma verdade), mas que são criadas, produzidas ou distribuídas por "agentes" que pretendem prejudicar em vez de servir ao interesse público. Essas más informações - como informações verdadeiras que violam a privacidade de uma pessoa sem justificativa de interesse público - vão contra os padrões e a ética do jornalismo (WARDLE; DERAKHSHAN, 2018, p. 44).

Na proposta dos autores, a diferença entre Informação Incorreta e Desinformação está na intencionalidade e no nível de consciência de quem produz a informação falsa. Entendemos, ao refletir sobre o primeiro elemento, que há uma necessidade de observar que elas podem ser alteradas dependendo da perspectiva de produção e emissão do conteúdo, seja ele primário (produtor da informação) ou secundário (uma pessoa que compartilhar).

Um conteúdo pode ser produzido na perspectiva de Informação Incorreta e ser compartilhada como Desinformação por outro espaço. São concepções que se retroalimentam. Esse tipo de raciocínio deve ser aplicado em todo o processo de classificação.

${ }^{6}[\ldots]$ It is a deliberate, intentional lie, and points to people being actively disinformed by malicious actors. 
Importante destacar também que os pontos elencados como tipos de Desordem Informacional estão conectados ao Segundo Elemento: as fases de criação da desordem informacional. Na criação, produção e distribuição da mensagem, os primeiros têm relação com a transformação de informações em conteúdos midiáticos. Distribuição, como o nome já diz, refere-se aos canais em que essas informações são circuladas. Eles estão imbricados porque precisam ser pensados para que tenham grande circulação.

Com os cidadãos munidos de suportes eletrônicos digitais, sejam eles móveis ou não, e dotados de uma alfabetização de softwares conectados à rede, há de forma descentralizada a execução dessas três fases. Enquanto os primeiros são os tipos, este segundo elemento é caracterizado como as fases de criação do primeiro. Este contexto possibilita que o primeiro aconteça de forma mais fluida e dinâmica, não ficando mais circunscrito aos meios de comunicação de massa (e seus proprietários). Esse ponto, com os seus desdobramentos, é mais nebuloso, mas entendemos que é possível observar com mais facilidade os canais de circulação.

A terceira forma são os tipos que compõem o fenômeno: agente, mensagem e intérprete. Nesse elemento, estão os aqueles que criam, produzem e distribuem os conteúdos, sendo importante ressaltar que há agentes (públicos ou privados) que possuem um maior impacto quando distribuem esses acontecimentos. Isso deve ser levado em consideração tanto de forma micro (grupos de família, por exemplo), como macro (declaração em redes sociais).

Como estamos falando de mensagens digitalizadas, essas podem assumir a forma de textos, imagens (sejam fotografias, infográficos e até memes), áudios, vídeos ou todos os formatos integrados. O intérprete é aquele que recebe a mensagem.

Apresentados esses pontos, é importante frisar que quando este trabalho se refere à terminologia Fake News, ela não representa uma notícia falsa como gênero jornalístico, mas sim as diferentes estratégias comunicacionais utilizadas na produção e propagação de informações enganosas (ROCHLIN, 2017). Entram nessa perspectiva sátiras e paródias jornalísticas, informações fora de contexto, bem como propagandas, publicidades, jornalismo e relações públicas. 


\section{VERIFICAÇÃO COMO ROTINA}

A apuração no jornalismo não é uma prática nova e, apesar de não existir um momento exato na literatura sobre o seu surgimento, certamente suas bases estão marcadas pelas transformações profundas ocorridas na profissão nos séculos XIX e XX (ROSHCO, 1975; SCHUDSON, 2010), períodos de criação e aperfeiçoamento de métodos. Esse movimento inicial materializa o conjunto das práticas, normas, valores e conhecimentos que assentam, orientam e direcionam os jornalistas na contemporaneidade.

Quando citamos o termo 'jornalismo', nos referimos ao conjunto ou à globalidade de um fenômeno que vai abarcar o método como instituição e como atividade prática. Para Franciscato (2003, p. 22), "Estas duas dimensões são manifestações interligadas do mesmo fenômeno” e complementa: “A 'instituição jornalística' está relacionada ao aspecto coletivo e organizacional do jornalismo, [...], que aglutina, organiza e dá unidade a normas de ação e valores culturais institucionalizados". Esse processo transformou o individualismo em uma atividade organizacional e realizada em coletivo, sendo "A instituição jornalística é, ao mesmo tempo, um 'corpo', uma forma social e uma estrutura operacional de produção." (FRANCISCATO, 2003, p. 22).

Para este trabalho, interessam-nos as práticas relacionadas à apuração e à verificação dos fatos selecionados por esses profissionais. Com isso, levamos em conta as dimensões citadas para lançar um olhar às práxis de apuração. Trata-se de um conjunto de procedimentos que acompanham de forma circular o trabalho do jornalista. São essas metodologias que garantirão a precisão das informações divulgadas e que diferenciarão o jornalismo da literatura (BAHIA, 1990). Pereira Junior (2009, p. 70 e 71) enfatiza: "Seu trabalho é ser categórico: um fato ocorreu deste jeito, não de outro" e Santi reforça:

[...] falar em método de apuração jornalística significa falar de um conjunto de práticas (habilidades e técnicas) executadas pelos jornalistas, como por exemplo a observação de eventos e de seus desdobramentos, entrevista com fontes de informações, leitura de documentos e outros dados de natureza técnica etc. (SANTI, 2010, p. 9).

Tanto em redações como em trabalhos acadêmicos, as terminologias apuração e verificação são usadas de diferentes formas, às vezes como sinônimas, outras de forma distinta. Para o nosso trabalho, elas assumem feições idênticas e acontecem em diferentes momentos das rotinas de produção. Essa mistura conceitual ganha volume com a Desordem 
Informacional (WARDLE; DERAKHSHAN, 2018), que demandou a criação de setores de verificação (fact-checking) nas empresas e o surgimento de novas agências especializadas em checagem de fatos. De acordo com dados do Duke University Reporter's Lab ${ }^{7}$, no mundo há 187 iniciativas de fact-checking em funcionamento.

A verificação é parte fundamental no processo de produção e disseminação de informações (BRANDTZAEG et al., 2015). O American Press Institute explica que “o objetivo de empreendimentos de fact-checking é refazer o trabalho de reportagem e pesquisa a partir de declarações verificáveis de políticos e pessoas públicas cujas palavras geram impacto na sociedade" (GEHRKE, 2017, p. 133).

O que defendemos é que essas práticas sempre foram adotadas nas redações, sendo alteradas de acordo com o desenvolvimento tecnológico e da profissão. A partir das ideias de Lippmann (1995), Kovach e Rosenstiel (2004) definiu-se o jornalismo como uma "disciplina de verificação", proposta que não diferencia as terminologias (apuração e verificação) e se aproxima da ideia clássica do jornalismo como guardião da verdade.

Diferentes métodos têm sido empregados (STOCKING; GROSS, 1989; FISHMAN, 1988; KOVACH; ROSENSTIEL, 2004; PEREIRA JUNIOR, 2009) para orientar profissionais no processo de apuração e têm colaborado para a exatidão dos fatos noticiáveis. É o caso de Philip Meyer (1993), que defende a utilização de métodos científicos de investigação social e comportamentos na prática jornalística para levantar e analisar dados. O pesquisador propõe alguns fundamentos para a prática: análise de estatísticas oficiais e de informes sociológicos; cruzamento de dados de diferentes origens (jurídicos, biomédicos, político-financeiros etc.); informação, análise e realização de sondagens de opinião, com especial referência às atividades eleitorais; desenho e realização de experimentos psicossociais para reportagens ilustrativas sobre atitudes e problemas socioculturais da comunidade.

\section{PRODUÇÃO DA AGÊNCIA HOLOFOTE}

Lançada em $1^{\text {o }}$ de janeiro de 2019 pelo Correio Braziliense, a Holofote ${ }^{8}$ é a primeira iniciativa de checagem de fatos de um jornal no Distrito Federal. Fazem parte da equipe os editores Leonardo Meireles e Leonardo Cavalcanti, os subeditores Guilherme Goulart e Igor

\footnotetext{
${ }^{7}$ Informação extraída em 26 de julho de 2019. Disponível em: https://reporterslab.org/fact-checking/.

${ }^{8} \mathrm{O}$ site pode ser acessado em: https://www.correiobraziliense.com.br/holofote/.
} 
Silveira e a repórter Ana Carolina Fonseca. Não há hierarquia no setor, nem um profissional possui dedicação exclusiva à área e todos atuam de acordo com as demandas do dia.

O site do projeto informa que os passos da International Fact-Checking Network $(\text { IFCN })^{9}$, rede mundial de checadores, serão balizadores do trabalho e utilizados como critérios declarados: apartidarismo e equidade; transparência das fontes; transparência de financiamento e organização; transparência de método; e correções francas e amplas.

As sugestões de conteúdos a serem verificados chegam à redação a partir de canais como WhatsApp, e-mail, redes sociais (possuem conta no Twitter e Facebook), por telefone, além de, individualmente, os membros receberem recomendações de colegas da redação ou de cidadãos. As entrevistas dadas ao CB.Poder, um programa que é parceria do Correio com a TV Brasília, também são fonte de verificação de declarações. Ainda, entrevistas em programas concorrentes podem igualmente ser alvo de apuração. Com isso, duas perspectivas são averiguadas: informações pontuais, que circulam como possíveis desinformações, e entrevistas de pessoas proeminentes.

$\mathrm{O}$ setor criou nove selos para marcar os conteúdos verificados. O primeiro é " $\mathrm{Na}$ Mosca", quando a informação é comprovadamente verdadeira; "Quase Lá" significa que o dado é parcialmente correto e precisa de esclarecimentos; em "Pisou na Bola", a informação é comprovadamente incorreta ou falsa; no "Calma Aî", a "notícia" ou dado é exagerado e coloca em xeque a publicação; “Ó A Montagem” sinaliza que a fonte se valeu de ferramentas digitais para modificar áudio, foto ou vídeo.

Ainda existem as rubricas "Mudou de Ideia", quando há uma contradição que ameaça a credibilidade da informação; "Sub Judice", a qual diz que a equipe precisa de mais tempo para atestar a veracidade das informações; "Mistério", que declara faltarem dados e fontes capazes de comprovar a informação; e, por fim, "Cabo de Guerra", informações conflitantes que impedem/prejudicam a comprovação.

Nos primeiros seis meses de funcionamento, o núcleo fez 94 publicações, das quais 43 checagens foram classificadas como desinformação. A totalidade dessas mensagens são multimídia e oriundas de comunicadores como o WhatsApp e mídias sociais. Trata-se de informações que circulam em sua grande maioria na internet e são produzidas e/ou compartilhadas com o objetivo de prejudicar e tirar proveito. Apesar de identificar que a

\footnotetext{
${ }^{9}$ Disponível em: https://www.poynter.org/ifcn/.
} 
origem é das mídias sociais, não foi possível confirmar a autoria das mensagens. Isso se deve certamente porque as checagens não buscam esse tipo de dado e à Holofote interessa somente identificar a veracidade do fato. Trata-se de uma tendência mundial, mas que, dada a importância ética de identificar a fonte de informações equivocadas, precisaria ser revista e/ou reconsiderada, embora não seja o foco deste trabalho.

Nem todos esses conteúdos receberam selos, como é o caso da postagem "Copo de cloro para combater o mosquito Aedes aegypti? Não caia nessa"10. Na publicação, é atestada a falsidade da informação, mas os selos não são atribuídos. Na observação, é possível ainda identificar que somente alguns materiais publicados não possuem selos, o que não acontece com as verificações das entrevistas, já que todas os possuem.

Os temas de maior impacto social e interesse público tendem a ser priorizados na escolha do que será verificado, como esclarece Fonseca (2019): "Não temos critérios formalizados para escolher [os assuntos que serão verificados], mas depende muito da viabilidade de verificar certa coisa, do tempo que demanda/tempo que temos, e como imaginamos que essa verificação impactaria o leitor". Assuntos locais e alguns nacionais com impacto regional ganham maior atenção na escolha.

O trabalho da equipe aumenta nos momentos de crise, já que esses são mais propícios para a circulação de desinformação, e notícias falsas sempre aparecem com maior intensidade nesses períodos. O rompimento da barragem de Brumadinho é um exemplo que foi acompanhado de perto pelo Núcleo.

Não há consenso entre os profissionais da redação quando o tema é diferenciar a prática de verificação e apuração. Guilherme (2019) entende que, em ambos os casos, a intenção é verificar a veracidade da informação e esclarecer, por isso não vê diferença entre os dois termos.

Já para a repórter Carolina (2019), apuração e verificação são coisas distintas. Pela explicação da jornalista, a apuração é mais ampla e "[...] O verificar, na minha opinião, é ir em busca de algo específico; ter uma informação, fala, afirmação etc. e buscar a corroboração ou negação dela”. Segundo afirmou, cada assunto demanda um tipo de verificação diferente.

Igor Silveira (2019), por sua vez, não tem muita certeza se há distinção entre apuração e verificação. Ele acredita que a diferenciação principal desse trabalho atual é que "não há

${ }^{10}$ Disponível em: http://bit.ly/2ykBpxD. 
necessidade de descobrir uma história e sim identificar se há inverdades na história. Na verificação, nós somos provocados e no outro o jornalista provoca."

O Núcleo de Verificação Correio Brasiliense, a Agência Holofote, também é responsável por averiguar entrevistas produzidas e veiculadas pelo jornal ou pelos concorrentes. O foco dessa atividade é analisar a fala dos entrevistados e constitui-se como a prática mais longa do setor, podendo cada investigação demorar de dois a três dias para ser concluída. A demora acontece porque muitos temas são examinados e uma variedade de estratégias e fontes são utilizadas para se chegar ao resultado esperado, mas a delonga é proveniente, principalmente, da quantidade de informações que são examinadas.

Ao observar as comprovações dos discursos produzidos nas entrevistas, é possível perceber que nem todo o conteúdo das entrevistas é falso ou distorcido. Há elementos que são conflituosos. A transparência das fontes em alguns conteúdos é feita de forma hipertextual, remetendo links para as fontes consultadas.

É interessante notar que todos os 32 conteúdos classificados como Informação Incorreta em nossa pesquisa são verificações de entrevistas concedidas por autoridades públicas. Como discutimos na parte teórica, é complexo identificar intencionalidade em incorreções em falas amplas. Por isso, acabamos classificando como Informações Incorretas 32 verificações que estão enquadradas nesse formato de trabalho. Vale destacar também que nem todo o conteúdo é errado.

Os dois tipos de conteúdos que são publicados demandam estratégias a serem seguidas. As opiniões dos entrevistados se aproximam quando o tema é a existência de rotinas de apuração. Para Guilherme, (2019), as estratégias são diversificadas e cada profissional adota uma tática diferente: "Eu percebo que, quando a gente divide a apuração, a gente vê que caminhos cada um seguiu". Ele explica haver profissionais que recorrem bastante a especialistas, outros preferem explorar a internet, isso dependendo sempre do assunto que esteja sendo pesquisado.

Carolina (2019) opina que existe rotina no processo de verificação, "mas cada verificação segue uma ordem diferente". O primeiro passo, de acordo com a jornalista, é entender o assunto e contextualizar. Depois disso, a repórter afirma que precisa fazer pesquisas, buscar fontes e arquivos que corroborem a verificação. Fontes oficiais e assessorias de imprensa são destacadas: "Sim, fazemos um pouco de tudo isso, dependendo da 
informação, mas às vezes o contato com a assessoria vem primeiro, depois pesquisas, ou viceversa" (FONSECA, 2019).

Já Igor (2019) entende que não há um passo a passo e que a origem da informação não vai alterar o processo de checagem. "Basicamente vamos nas fontes mais confiáveis. Se for sobre multa o tema, nós vamos ao Detran".

O dia a dia de trabalho tem indicado a Guilherme (2019) que a origem da informação vai estabelecer a dificuldade ou a facilidade de checar. Para ele, isso altera todo o processo de averiguação. O jornalista cita como exemplo uma checagem de entrevista dada pelo presidente da Câmara dos Deputados, Rodrigo Maia, quando ele afirmou que a votação da Reforma da Previdência foi a que teve mais quórum na história da Casa. O repórter foi procurar na internet a informação e não encontrou nada. "Automaticamente eu pensei em colocar uma etiqueta mistério, mas nesse caso eu liguei para a assessoria dele". O jornalista diz que a assessoria mandou um relatório com o timbre da mesa diretora da Câmara mostrando que o levantamento estava correto.

Apesar de deixar claro que o contato com a assessoria de imprensa nem sempre é confiável, Guilherme (2019) diz que, em alguns momentos, elas ajudam. Ele acredita que essa troca deve ser sempre com parcimônia, porque a fonte é envolvida com o assunto, portanto, "É uma prática a ser evitada porque a informação pode estar contaminada."

Igor (2019) segue o mesmo pensamento e indica que um dos desafios citados, e que pode virar um problema na checagem, são as assessorias de imprensa, pois muitas vezes só refirmam informações passadas pelos seus gestores. Em alguns momentos, não existem outras fontes para confrontar a informação.

A produção e circulação de conteúdo em diferentes formatos (áudios, vídeos, fotos) altera e diversifica os métodos de apuração. Segundo Guilherme (2019), há uma variedade de ferramentas que possibilitam verificar fotos e outros formatos, e que os profissionais que trabalham nesse posto precisam conhecer. Carolina (2019) acha que o modelo de produção em formatos diferentes não dificulta, "O que dificulta mesmo é o modo de circulação. O mais difícil, em muitos casos, é saber a origem do boato ou informação para começar a apurar”.

Um outro desafio para o Núcleo são as informações conflitantes de várias fontes. Quando isso acontece, há uma necessidade de cuidado redobrado que demanda uma verificação com uma avaliação mais acurada, pois, como reforça Goulard (2019), “Tudo que 
se encontrar no caminho da verificação pode e deve ser escrito em nome do esclarecimento e da boa informação".

Igor (2019) revela haver conteúdos que os jornalistas percebem facilmente serem falsos. Erros exagerados de português e qualidade gráfica muito baixa são apenas alguns exemplos de identificação do conteúdo duvidoso, mas, às vezes, não existem elementos para se afirmar ou não a veracidade de um dado. Nesses casos, eles deixam claro que o conteúdo não é passível de ser verificado. "Dizer para o leitor que nós não temos certeza se aquilo é certo" é uma forma de alertá-lo. O papel desse tipo de alerta é avisar que a informação circula, mas não está comprovada.

É possível encontrar informações compartilhadas por usuários que não têm consciência da falsidade da matéria, como é o caso do conteúdo verificado "Atenção! Vídeo de alagamento na UnB não é de 21 de abril de 2019”. Isso não quer dizer que esse vídeo não tenha sido produzido para causar problema. O próprio vídeo continha a informação que desmentia a publicação e o usuário admitia o erro.

Assim, quem incentiva a verificação dos discursos é o próprio personagem, não a circulação do conteúdo. Nos textos em que são averiguados os discursos, há somente uma menção à entrevista, não sendo eles disponibilizados na íntegra e sim somente partes deles.

Informações conflitantes, mesmo sem comprovação do jornalista, podem ser publicadas pelas agências de checagem em alguns momentos. Quando isso acontece, para sinalizar existem etiquetas como a "Mistério", quando não dá para verificar, por exemplo, "Mas aí deixamos claro que foi dito pela pessoa, é o que ela alega, mas não comprovado" (FONSCECA, 2019).

Ao todo, 17 conteúdos publicados pela Holofote não têm relação com verificação. São entrevistas com especialistas, conteúdos sobre checagem e balanço da semana feitos pelos jornalistas. Duas postagens foram consideradas verídicas e por isso não foram classificadas.

\section{CONSIDERAÇÕES}

Os dados desta pesquisa indicam que o surgimento das agências de checagem não representa uma ressignificação do processo de verificação e apuração. Há novas ferramentas e estratégias adotadas pelos jornalistas, mas não são as agências que as criam. Essas práticas 
são oriundas da experiência histórica da profissão e foram sendo desenvolvidas a partir das demandas sociais e das mudanças tecnológicas.

Com isso, não estamos querendo dizer que não existem ritos nos núcleos de checagem. Não há dúvidas da existência de rotinas de produção nesse processo. As entrevistas mostram que, apesar de não serem claras para os profissionais, elas são adotadas, e cada um tem optado por métodos diferentes de acordo com a demanda de cada checagem. Isso nos leva a crer que pesquisas que busquem sistematizar práticas de acordo com tipos de informação checada seriam frutíferas no sentido de criar um arcabouço consistente de práticas a serem seguidas por outros profissionais e por futuros jornalistas.

A impossibilidade de identificar os autores da desinformação traz à tona também a necessidade de que pesquisas invistam em todo o circuito de criação, produção e circulação dessas informações. Indica também aos jornalistas e suas empresas a necessidade de investimentos para esse tipo de identificação. Caberia elaborar reportagens sobre a temática, e estratégias de produção, canais de circulação e identificação de autoria são possíveis pautas a serem desenvolvidas.

É importante destacar também que novas pesquisas utilizando observação participante, e com um corpus maior de agências, precisam ser realizadas para o mapeamento sistemático de práticas. Seria interessante que essas observações se dessem a partir de diferentes conteúdos e profissionais para abarcar um maior número de estratégias adotadas.

\section{REFERÊNCIAS}

BAHIA, Juarez. Jornal, História e Técnica: as técnicas de jornalismo. 4. ed. São Paulo: Ática, 1990.

BRANDTZAEG, Patter Bae et al. Emerging journalistic verification practices concerning social media. Journalism Practice. Londres: Routledge, v. 10, n. 3, p. 232-342, 2015.

BURKHARDT, Joanna M. History of Fake News. Library Technology Reports, [S.l.], v. 53, n. 8, p. 5-9, 2017.

FISHMAN, Mark. Manufacturing the news. Austin: University of Texas Press, 1988.

FONSECA, Ana Carolina. Entrevista concedida a Alberto Marques. Brasília, 26 jul. 2019.

FRANCISCATO, Carlos Eduardo. A atualidade no jornalismo: bases para sua delimitação teórica. 2003. Tese (Doutorado) - Universidade Federal da Bahia, Salvador. 2011. 
GEHRKE, Marília. O áudio do presidente: ética, fontes, verificação e fact-checking no jornalismo. Revista Comunicação, Cultura e Sociedade, Alto Araguaia, MT, n. 7, v. 7, p. 133-146, 2017.

GOULART, Guilherme. Entrevista concedida a Alberto Marques. Brasília, 26 jul. 2019.

IRETON, Cherilyn; POSETTI, Julie (Eds.). Journalism, 'Fake News' \& Disinformation: Handbook for journalism education and training. Paris: Unesco, 2018.

KOVACH, Bill; ROSENSTIEL, Tom. Os elementos do jornalismo: O que os jornalistas devem saber e o público exigir. São Paulo: Geração Editorial, 2004.

LEMOS, André. Ciber-Cultura-Remix. In: SEMINÁRIO SENTIDOS E PROCESSOS, 2005, São Paulo. Anais [...]. São Paulo: Itaú Cultural, 2005. Disponível em: http://bit.ly/2ylH3PM. Acesso em: 10 jul. 2017.

LIPPMANN, Walter. Liberty and the News. New Brunswick, NJ: Transaction Publishers, 1995.

MEYER, Philip. Periodismo de precision: nuevas fronteras para la investigación periodística. Barcelona: Bosch, 1993.

PEREIRA JUNIOR, Luiz Costa. A apuração da notícia: Métodos de investigação na imprensa. 2. ed. Petrópolis: Vozes, 2009.

ROCHLIN, Nick. Fake news: belief in post-truth. Library Hi Tech, [s.l.], v. 35, n. 3, p. 386-392, 2017.

ROSHCO, Bernard. Newsmaking. Chicago: University of Chicago Press, 1975.

SANTI, Vilso Junior. O desafio da apuração jornalística no ciberespaço. Sessões do Imaginário, Porto Alegre, n. 24, p. 8-17, fev. 2010.

SCHUDSON, Michael. Descobrindo a notícia: uma história social dos jornais nos Estados Unidos. Petrópolis: Vozes, 2010.

SHAPIRO, Ivor et al. Verification as a Strategic Ritual: How Journalists Retrospectively Describe Processes for Ensuring Accuracy. Journalism Practice, v. 7, n. 6, p. 657-673, 2013.

SILVEIRA, Igor. Entrevista concedida a Alberto Marques. Brasília, 26 jul. 2019.

STOCKING, S. Holly; GROSS, Paget H. How do journalists think? A proposal for the study of cognitive bias in Newsmaking. Bloomington: Eric Clearinghouse on Reading and Communication Skills, 1989.

TANDOC Jr., Edson C.; ZHENG, Wei Lim; LING Richard. Defining "Fake News": A typology of scholarly definitions. Digital Journalism, v. 6, n. 2, p. 137-153, 2018. Disponível em:

http://bit.ly/2Mmp5oJ. Acesso em: 20 mar. 2019.

WARDLE, Claire; DERAKHSHAN, Hossein. Information Disorder: Toward an interdisciplinary framework for research and policy making. Strasbourg: Council of Europe, 2017. 
WARDLE, Claire; DERAKHSHAN, Hossein. Thinking about 'information disorder': formats of misinformation, disinformation, and mal-information. In: IRETON, Cherilyn; POSETTI, Julie (Eds.). Journalism, 'Fake News' \& Disinformation: Handbook for journalism education and training. Paris: Unesco, 2018.

Original recebido em: 19 de dezembro de 2019

Aceito para publicação em: 01 de outubro de 2020

Alberto Marques

Professor do Mestrado em Inovação em Comunicação e Economia Criativa da Universidade Católica de Brasília (UCB). Tem interesse em assuntos relacionados à cibercultura e inovação, com foco em comunicação organizacional, comunicação pública e jornalismo digital. É doutor em comunicação pelo Programa de Pós-graduação em Comunicação da Universidade de Brasília, com estágio de doutoramento no exterior (bolsa sanduíche Capes) no Departamento de comunicação da Universidade da Beira Interior (UBI - Portugal). Editor da Revista Comunicologia.

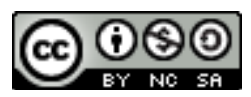

Esta obra está licenciada com uma Licença

Creative Commons Atribuição-NãoComercial-CompartilhaIgual 4.0 Internacional 